Article

\title{
Development of Poly(2-Methacryloyloxyethyl Phosphorylcholine)-Functionalized Hydrogels for Reducing Protein and Bacterial Adsorption
}

\author{
Temmy Pegarro Vales ${ }^{1,2,+}{ }^{\mathbb{D}}$, Jun-Pil Jee ${ }^{3, \dagger}$, Won Young Lee ${ }^{3}$, Sung Cho ${ }^{4}$, Gye Myung Lee ${ }^{5}$, \\ Ho-Joong Kim ${ }^{1,5}$ and Jung Suk Kim ${ }^{6, *}$ \\ 1 Department of Chemistry, Chosun University, Gwangju 501-759, Korea; valestemmy@gmail.com (T.P.V.); \\ hjkim@chosun.ac.kr (H.-J.K.) \\ 2 Department of Natural Sciences, Caraga State University, Butuan City 8600, Philippines \\ 3 College of Pharmacy, Chosun University, Gwangju 501-759, Korea; jee@chosun.ac.kr (J.-P.J.); \\ ovilion777@naver.com (W.Y.L.) \\ 4 Department of Chemistry, Chonnam National University, Gwangju 61186, Korea; scho@chonnam.ac.kr \\ 5 Department of Carbon Materials, Chosun University, Gwangju 61452, Korea; vkehdi@korea.kr \\ 6 Department of Orthopaedic Surgery, Graduate School, College of Medicine, Kyung Hee University, \\ Seoul 02447, Korea \\ * Correspondence: maeno70@daum.net \\ + These authors contributed equally to this work.
}

Received: 15 January 2020; Accepted: 19 February 2020; Published: 20 February 2020

check for updates

\begin{abstract}
A series of hydrogels with intrinsic antifouling properties was prepared via surfacefunctionalization of poly(2-hydroxyethyl methacrylate) [p(HEMA)]-based hydrogels with the biomembrane-mimicking zwitterionic polymer, poly(2-methacryloyloxyethyl phosphorylcholine) [p(MPC)]. The $\mathrm{p}(\mathrm{MPC})$-modified hydrogels have enhanced surface wettability, high water content retention $(61.0 \%-68.3 \%)$, and good transmittance $(>90 \%)$. Notably, the presence of zwitterionic MPC moieties at the hydrogel surfaces lowered the adsorption of proteins such as lysozyme and bovine serum albumin (BSA) by $73 \%-74 \%$ and $59 \%-66 \%$, respectively, and reduced bacterial adsorption by approximately $10 \%-73 \%$ relative to the unmodified control. The anti-biofouling properties of the $\mathrm{p}$ (MPC)-functionalized hydrogels are largely attributed to the dense hydration layer formed at the hydrogel surfaces by the zwitterionic moieties. Overall, the results demonstrate that biocompatible and antifouling hydrogels based on $\mathrm{p}(\mathrm{HEMA}) \mathrm{p}(\mathrm{MPC})$ structures have promising potential for application in biomedical materials.
\end{abstract}

Keywords: biomembrane-mimicking; hydrogel; protein adsorption; surface-functionalization; wettability

\section{Introduction}

Significant interest has emerged in the development and design of functional biomaterials with excellent biocompatibility and antibiofouling properties. A promising biomaterial that has long been investigated for diverse biomedical and industrial applications is the hydrogel, which consists of three-dimensional cross-linked hydrophilic polymeric networks capable of retaining large amounts of water and biological fluids [1,2]. Parhi has comprehensively reviewed the different types of cross-linking-based hydrogels for various pharmaceutical applications including small-molecule cross-linked hydrogels, polymer-polymer cross-linked hydrogels, photo cross-linked hydrogels, enzymatic cross-linked hydrogels, and interpenetrating networks [3]. In particular, poly(2-hydroxyethyl methacrylate) [p(HEMA)]-based hydrogels have been successfully commercialized worldwide as bulk materials for the development and production of biomedical materials such as urethral catheters [4], 
neural tissue devices [5], dental adhesives [6], implantable drug delivery systems [7], and contact and intraocular lenses [8-11]. This is largely due to their essential and desirable attributes, including high water retention capacity, broad biocompatibility, and physical features that resemble living soft tissues [12]. Moreover, p(HEMA)-based hydrogels are more inert to normal biological processes, permeable to metabolites, and are capable of withstanding a very high temperature sterilization without incurring physical damage in comparison to other types of hydrogels such as poly(ethylene glycol) diacrylate (PEGDA), gelatin methacryloyl (GELMA), and others [13]. While p(HEMA) hydrogels exhibit excellent biocompatibility, its fouling, albeit low, is still higher than other nonfouling materials. Moreover, its hydration is lower in comparison to that of native tissue [14], which is actually a particular major issue impeding the development of functional hydrogels: the adherence of proteins and other foulants following the implantation of these biomaterials in the biological environment [15]. Nonspecific adsorption of protein and other biomolecules plays a significant role in the development of undesirable biological responses, including inflammation, blood clotting, biofilm formation, cell adhesion, bacterial adhesion, and bacterial infection [16]. Thus, there is a growing need to develop biomaterials that inhibit or reduce nonspecific protein adsorption and resist bacterial adhesion and colonization.

The surface functionalization utilizing second hydrophilic polymers such as polysaccharides (e.g., dextran and hyaluronic acid and) [17,18], poly(ethylene glycol) (PEG) [19-22], and biomembranemimicking zwitterionic polymers [e.g., 2-methacryloyloxyethyl phosphorylcholine (MPC) and carboxybetaine methacrylate (CBMA)] [23-25] is one such strategy to develop such "protein-resistant" biomaterials. These polymers are incorporated on biomaterial surfaces using a diverse set of surface coating and modification techniques, including physical adsorption, graft polymerization, self-assembled monolayers (SAMs), layer-by-layer assembly, interpenetrating polymer network (IPN), surface-initiated atom transfer radical polymerization (ATRP), and conventional free-radical polymerization [26-34]. Among these methods, the free-radical polymerization seems the most common reaction employed in the development of surface-modified hydrogels. Recently, a review article by Choi et al. highlighted the recent advances on the most commonly used photocross-linkable hydrogels, including PEGDA, GELMA, and methacrylated hyaluronic acid for several biomedical applications [35].

One of the recognized next-generation antifouling biomaterials is the zwitterionic polymers, largely due to their ability to form hydration shell via electrostatic interactions, bringing about tighter and denser adsorbed water [36,37]. There are two main classes comprising the zwitterionic polymers namely polybetaines and polyampholytes. The typical polybetaines such as poly(sulfobetaine methacrylate) [p(SBMA)], poly(carboxybetaine methacrylate) [p(CBMA)], and poly(2-methacryloyloxyethyl phosphorylcholine) $[\mathrm{p}(\mathrm{MPC})]$ have their charged groups located on the pendant side chains of same monomer units [38]. Polyampholytes, on the other hand, are zwitterionic polymers whose charged groups are located on different monomer units and can be prepared from copolymerization of equimolar quantities of positively charged and negatively charged monomers. Schroeder, et. al. have prepared multifunctional polyampholytes hydrogels comprising positively charged [2-(acryloyloxy)ethyl] trimethylammonium chloride (TMA) and negatively charged 2-carboxyethyl acrylate (CAA) moieties [39]. However, one difficulty usually encountered with using polyampholytes as antifouling materials is that the charged groups are not homogeneously arranged. It is imperative to have surfaces with charged groups that are homogeneously arranged to minimize the effects of any acid-base interactions with the material and achieve an optimal environment in generating a densely hydration layer [40].

Among a wide range of biocompatible zwitterionic polybetaines, poly(2-methacryloyloxyethyl phosphorylcholine) [p(MPC)] appears to be a promising anti-fouling biomaterial. MPC-containing polymeric materials are used as anti-fouling agents because the external surface of cellular membranes is rich in phospholipids possessing zwitterion headgroups, particularly phosphatidylcholine [41]. Hence, MPC-surface-modified biomaterials are likely to mimic cell membranes and be highly biocompatible [42]. Several biocompatible polymers such as polyethylene, segmented polyetherurethane (SPU), siloxane polymers, and poly(tetrafluoroethylene) (PTFE) have been modified to generate surfaces with antifouling properties [43-45]. The anti-fouling properties of these MPC-coated surfaces are highly correlated with 
the formation of an excellent hydration layer. This hydration layer leads to a strong repulsive force against the surrounding proteins and prevents the generation of any prime layer that might otherwise surfaces are strongly related to the large fraction of free water retained around the polymeric chains, which facilitate microorganisms to anchor onto the surface $[46,47]$.

Herein, we prepared a series of $\mathrm{p}(\mathrm{MPC})$-surface-functionalized [p(HEMA)] hydrogels employing a facile free-radical polymerization reaction, and the adsorption of protein and bacteria onto the p(MPC)-coated surfaces was evaluated. Comprehensively studied bovine serum albumin (BSA) and lysozyme were selected as model proteins [48], while gram-negative Escherichia coli was used for the in-vitro bacterial desorption experiment. Furthermore, the effects of surface-functionalization with $\mathrm{p}(\mathrm{PMC})$ on surface wettability, equilibrium swelling, and optical transmittance of the resultant hydrogels were investigated.

\section{Materials and Methods}

\subsection{Chemicals and Equipment}

Hydroxyethyl methacrylate (HEMA), ethylene glycol dimethacrylate (EGDMA), lysozyme (chicken egg lysozyme), and BSA were obtained from Sigma Aldrich (St Louis, MO, USA). 2-Methacryloyloxyethyl phosphorylcholine (MPC) was obtained from KCI Limited (Seoul, Korea). DifcoTMMueller-Hinton broth medium was purchased from Thermo Fisher Scientific (Leicestershire, UK), while azobisisobutyronitrile (AIBN) and benzophenone were procured from Junsei (Tokyo, Japan) and Daejung Chemical \& Metal Co. (Shiheung, Korea), respectively. Acetone, trifluoroacetic acid, and other solvents were of analytical grade and used without further purification. The transmittance spectra of the hydrogels were measured at 300-700 nm, in triplicate, using a Shimadzu ultraviolet-visible spectrophotometer 1601 PC (UV-1650PC) (Tokyo, Japan).

\subsection{Synthesis of HEMA-Based Hydrogels}

The HEMA monomer was initially vacuum-distilled before polymerization. Subsequently, EGDMA (0.04 g) and AIBN (0.04 g) were dissolved in HEMA (9.92 g) and mixed for $30 \mathrm{~min}$. The mixture was then injected into a square mold comprising two glass plates internally covered with a polypropylene sheet and separated by a $0.20 \mathrm{~mm}$-width Teflon frame. The samples were heated at $90{ }^{\circ} \mathrm{C}$ for $5 \mathrm{~h}$ to allow the polymerization to take place. After cooling to room temperature, samples were removed from the molds and placed in $400 \mathrm{~mL}$ de-ionized water for extensive dialysis. To completely remove unreacted monomer and initiators, the dialysis was carried out for $2 \mathrm{~d}$ by changing the water three times per day. Afterwards, square hydrogels $(10 \mathrm{~mm} \times 10 \mathrm{~mm} \times 2.4 \mathrm{~mm})$ were cleaved from the sample, submerged in boiling water for $15 \mathrm{~min}$, and dried at $40{ }^{\circ} \mathrm{C}$ overnight.

\subsection{Surface-Functionalization of $p(H E M A)$ Hydrogels with $p(M P C)$}

The $\mathrm{p}(\mathrm{HEMA})$ hydrogels were surface-functionalized with $\mathrm{p}(\mathrm{MPC})$ according to a previously reported procedure [34]. All reactions were carried out at room temperature. Initially, the p(HEMA) substrates were initially submerged in a benzophenone solution in acetone $(10 \mathrm{mg} / \mathrm{mL})$ for $1 \mathrm{~min}$ and vacuum-dried for $1 \mathrm{~h}$. Subsequently, $\mathrm{p}(\mathrm{HEMA})$ hydrogels with adsorbed benzophenone were immersed in a series of aqueous MPC solutions with monomer concentrations of $0.1 \mathrm{M}, 0.25 \mathrm{M}$, and $0.5 \mathrm{M}$. The samples were irradiated with UV-B $(\sim 320 \mathrm{~nm})$ using a customized lamp chamber composed of eight 15W G15T8E lamps (Sankyo-Denki, Tokyo, Japan). After $15 \mathrm{~min}$, the samples were removed from the lamp chamber and thoroughly washed with acetone and water to remove unreacted monomers, excess benzophenone, and benzopinacol by-products. To further eliminate any non-covalently attached polymer and excess acetone, MPC-surface-functionalized hydrogels were soaked in deionized water overnight. 


\subsection{Optical Transmittance Measurement of the $p(H E M A) / p(M P C)$ Hydrogels}

The transmission spectra of the hydrogels (average thickness of the prepared hydrogels $=2.4 \mathrm{~mm}$ ) were obtained using a Shimadzu, UV-1650PC spectrophotometer (Tokyo, Japan). Each measurement was carried out at a wavelength range of 300-700 $\mathrm{nm}$ at room temperature, with each measurement performed four times; here, the averaged results are reported.

\subsection{Equilibrium Swelling of the $p(H E M A) / p(M P C)$ Hydrogels}

The equilibrium swelling ratio (ESR) of the prepared hydrogels were measured gravimetrically at room temperature. Initially, all hydrogels were fully dried to a constant weight before the equilibrium swelling. Subsequently, the fully dehydrated hydrogels were allowed to swell to equilibrium by immersion in phosphate-buffered saline (PBS, $\mathrm{pH} 7.4$ ) and kept at room temperature for $24 \mathrm{~h}$. It is widely known that a 24-h equilibration time is sufficient for fully swelling hydrogel samples $[49,50]$. Then, samples were removed from the PBS, excess surface water was blotted off with tissue paper, and the weights of the swollen hydrogels were recorded. The ESR was calculated according to the following equation:

$$
\operatorname{ESR}(\%)=\left[\left(\mathrm{W}_{\mathrm{s}}-\mathrm{W}_{\mathrm{d}}\right) / \mathrm{W}_{\mathrm{d}}\right] \times 100
$$

where $\mathrm{W}_{\mathrm{s}}$ and $\mathrm{W}_{\mathrm{d}}$ denote the hydrogel weights at the equilibrium swelling and dry states, respectively. The average values of three measurements are reported for each sample.

\subsection{Contact Angle Measurement of the $p(H E M A) / p(M P C)$ Hydrogels}

The surface wettability of the hydrogels was characterized by the water contact angle. Each sample was measured using a drop shape analyzer (DSA100, Krüss GmbH, Hamburg, Germany). A drop $(4.5 \mu \mathrm{L})$ of nanopure water was positioned on the hydrogel surface and the static water contact angle was determined from the image using imaging software. Ten measurements were performed, and the averaged results are reported.

\subsection{Protein Desorption from the $p(H E M A) / p(M P C)$ Hydrogels}

Protein desorption was measured previously described [51]. The prepared hydrogels were initially immersed in $10 \mathrm{~mL}$ PBS (pH 7.4) and incubated in an incubator shaker at room temperature and $150 \mathrm{rpm}$ for $24 \mathrm{~h}$. Two artificial tear solutions containing $3.88 \mathrm{~g} / \mathrm{L}$ of bovine serum albumin (BSA) and $1.20 \mathrm{~g} / \mathrm{L}$ of chicken egg-white lysozyme in PBS were prepared. Subsequently, five samples of each hydrogel type were placed in a vial containing $10 \mathrm{~mL}$ of artificial tear solution and incubated at $37^{\circ} \mathrm{C}$ and $150 \mathrm{rpm}$ for $12 \mathrm{~h}$. Afterwards, the hydrogels were rinsed with PBS after the first period of incubation to remove unbound protein on the hydrogel surface, then rapidly placed into $0.1 \%$ trifluoroacetic acid in an acetonitrile/water 1:1 (v/v) extraction solvent and incubated in the dark at room temperature for $24 \mathrm{~h}$. The extracted solution was diluted to 1/10th using the mobile phase and then subsequently analyzed. A reverse-phase high-performance liquid chromatography system (HPLC Plus, Azura, Germany) was employed to quantify the concentration of proteins extracted from the hydrogels. Approximately $20 \mu \mathrm{L}$ of the mixed solution was injected into a C18 column (LUNA-C18, $4.6 \mathrm{~mm} \times 250 \mathrm{~mm}, 5 \mu \mathrm{m}$; Phenomenex, Torrance, CA, USA), and eluted using an isocratic mobile phase that was a mixture of $50 \%$ acetonitrile containing $0.1 \%$ trifluoroacetic acid and $50 \%$ water. The run time and flow rate were set to $20 \mathrm{~min}$ and $1.0 \mathrm{~mL} / \mathrm{min}$, respectively, and the samples were detected at $220 \mathrm{~nm}$ using a UV-detector (DAD 2.1L, Azura, Germany).

\subsection{In Vitro Bacterial Desorption Test of the $p(H E M A) / p(M P C)$ Hydrogels}

All hydrogel samples were sealed in a 70\% ethanol solution and transferred to sterile distilled water 1 day before the bacterial desorption experiment. A Mueller-Hinton medium solution was prepared to culture E. coli and approximately $1 \mathrm{~mL}$ of an $E$. coli stock solution was added to $50 \mathrm{~mL}$ of $21 \mathrm{~g} / \mathrm{L}$ sterilized Mueller-Hinton medium solution and incubated at $37^{\circ} \mathrm{C}$ for $6 \mathrm{~h}$. Subsequently, approximately $2 \mathrm{~mL}$ of 
the cultured E. coli solution was inoculated in $400 \mathrm{~mL}$ of sterilized Mueller-Hinton medium solution and incubated with mild shaking at $37^{\circ} \mathrm{C}$ for $12 \mathrm{~h}$. After the incubation, the resultant E. coli solution was transferred into a $1 \mathrm{~L}$ beaker, and three samples of each type were placed into a stainless-steel net-shaped container and immersed in the bacterial solution. The samples were placed in an orbital shaker at room temperature, and the bacteria were allowed to reach the sample surfaces evenly. After $6 \mathrm{~h}$ of incubation, the samples were quickly washed with sterile distilled water and incubated in $20 \mathrm{~mL}$ of sterilized Mueller-Hinton medium in an incubator shaker set at $37^{\circ} \mathrm{C}$ and $150 \mathrm{rpm}$. At a pre-determined time, approximately $1 \mathrm{~mL}$ of the culture samples was taken and absorbance was measured at $595 \mathrm{~nm}$ using a UV spectrophotometer (TU-1800, Korea Instruments Co., Ltd., Seoul, Korea).

\subsection{Statistical Analysis}

Student's t-test was used to statistically analyze unpaired data and compare the two mean values. In comparing more than two mean values, one-way analysis of variance (ANOVA) followed by Tukey's multiple-comparison test was employed. The $\mathrm{p}$-value $<0.05$ was considered statistically significant in all analyzes. All data were expressed as mean \pm standard deviation.

\section{Results and Discussion}

A series of antifouling hydrogels was prepared by following the three-step synthesis pathway presented in Scheme 1. Initially, the HEMA monomers were polymerized using EGDMA and AIBN as the cross-linking agent and free radical source, respectively. Upon thermal activation $\left(\sim 90{ }^{\circ} \mathrm{C}\right)$, the AIBN decomposes to two 2-cyanopropyl fragments with unpaired electrons that rapidly react with the nearby HEMA monomers and EGDMA crosslinkers hereby producing growing HEMA polymer chains crosslinked with EGDMA moieties. The subsequent two steps involved adsorption of benzophenone as a photosensitizer that exhibits a well-established photochemical reaction and the UV-induced free radical polymerization of MPC monomers onto the hydrogel surfaces. The irradiation around $\sim 320 \mathrm{~nm}$ converts the benzophenone into its excited triplet state, which abstracts a hydrogen atom from the $\alpha$-methyl group of the nearby MPC units to generate both the benzophenone radicals and MPC radicals capable of initiating polymerization of the MPC monomers onto the hydrogel surfaces [52]. Surface-functionalization was conducted in an aqueous environment with MPC concentrations of $0.10 \mathrm{M}, 0.25 \mathrm{M}$, and $0.50 \mathrm{M}$, each solution generating a hydrogel with intrinsic antifouling properties: $\mathrm{p}(\mathrm{HEMA}) / \mathrm{p}(\mathrm{MPC}) 0.1, \mathrm{p}(\mathrm{HEMA}) / \mathrm{p}(\mathrm{MPC}) 0.25$, and $\mathrm{p}(\mathrm{HEMA}) / \mathrm{p}(\mathrm{MPC}) 0.5$.

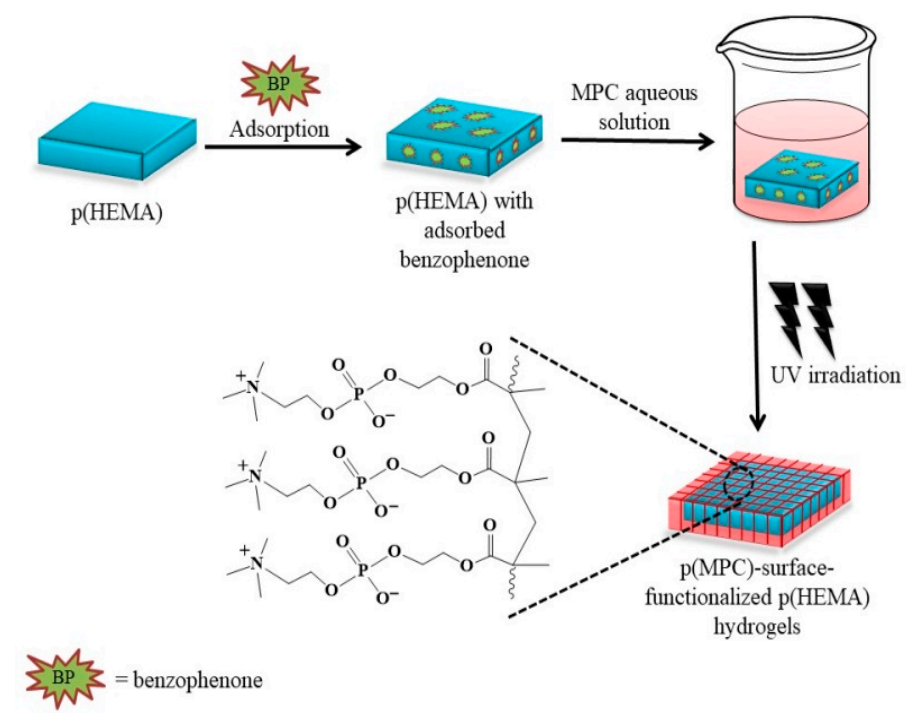

Scheme 1. Schematic illustration for the development of poly(2-hydroxyethyl methacrylate) [p(HEMA)]based hydrogels surface-functionalized with biomimetic poly(2-methacryloyloxyethyl phosphorylcholine) [p(MPC)]. 
As listed in Table 1, the hydrogels produced by a higher concentration of MPC showed higher amounts of $\mathrm{p}(\mathrm{MPC})$ on the substrate surfaces when compared to those produced by lower MPC concentrations. This result was highly anticipated because when there are more MPC monomers available for the polymerization reaction, the coverage of the hydrogel surfaces by the hydrophilic MPC moieties is increased. The quantities of $\mathrm{p}(\mathrm{MPC})$ per hydrogel surface of $\mathrm{p}(\mathrm{HEMA}) / \mathrm{p}(\mathrm{MPC}) 0.5$, $\mathrm{p}(\mathrm{HEMA}) / \mathrm{p}(\mathrm{MPC}) 0.25$, and $\mathrm{p}(\mathrm{HEMA}) / \mathrm{p}(\mathrm{MPC}) 0.1$ were estimated at $\sim 24.0, \sim 21.8$, and $\sim 18.0 \mu \mathrm{mol} / \mathrm{cm}^{2}$, respectively. The amounts of the conjugated $\mathrm{p}(\mathrm{MPC})$ in the synthesized hydrogels were determined using gravimetric measurements. Moreover, the effect of surface-functionalization with poly(MPC) on the hydrogel equilibrium swelling properties was investigated in a PBS medium at room temperature. High equilibrium water content is one of the typical features associated with hydrogels and various factors are known to control and affect the hydrogel swelling behavior, including the degree of ionization and the resulting interaction with counter ions, hydrophilic/hydrophobic balance of the hydrogels, and the hydrogel's effective crosslinking density [53]. Furthermore, the equilibrium swelling ratio (ESR) value increased, although not significantly, after the surface modification of the $\mathrm{p}(\mathrm{HEMA})$ hydrogels with $\mathrm{p}(\mathrm{MPC})$. The ESR of pristine $\mathrm{p}(\mathrm{HEMA})$ hydrogels was estimated at $60.1 \%$, while that of $\mathrm{p}$ (MPC)-modified hydrogels ranged from $61.0 \%$ to $68.3 \%$ ( $\mathrm{p}>0.05$ ). It should be noted that the hydrogel's swelling behavior was largely influenced by the effective crosslinking density of the $\mathrm{p}$ (HEMA) network as manifested by the negligible effect of the surface modification on the ESRs of the prepared hydrogels. Nevertheless, the obtained ESRs of hydrogels were in the range of low and intermediate water content (60-83\%), which reflect the optimal conditions for natural cartilage and high water content contact lenses [54,55].

Table 1. Characteristics of the poly(2-methacryloyloxyethyl phosphorylcholine)-surface-functionalized hydrogels.

\begin{tabular}{cccc}
\hline Hydrogels & $\begin{array}{c}\text { Amounts of Conjugated } \\
\text { poly(MPC) }\left(\boldsymbol{\mu m o l} / \mathbf{c m}^{\mathbf{2}}\right. \\
\text { per Hydrogel Surface) }\end{array}$ & $\begin{array}{c}\text { Equilibrium } \\
\text { Swelling Ratio }^{\mathbf{( \% )}}\end{array}$ & $\begin{array}{c}\mathbf{1} \\
\text { Contact Angle } \\
\left(^{\circ}\right)^{\mathbf{2}}\end{array}$ \\
\hline $\mathrm{p}(\mathrm{HEMA})^{3}$ & - & $60.1 \pm 1.1$ & $78.6 \pm 9.6$ \\
$\mathrm{p}(\mathrm{HEMA}) / \mathrm{p}(\mathrm{MPC}) 0.1$ & $18.0 \pm 1.2$ & $61.0 \pm 2.9$ & $74.7 \pm 9.7$ \\
$\mathrm{p}(\mathrm{HEMA}) / \mathrm{p}(\mathrm{MPC}) 0.25$ & $21.8 \pm 0.5$ & $61.6 \pm 1.0$ & $65.0 \pm 4.7^{4}$ \\
$\mathrm{p}(\mathrm{HEMA}) / \mathrm{p}(\mathrm{MPC}) 0.5$ & $24.1 \pm 1.8$ & $68.3 \pm 1.3$ & $59.2 \pm 7.0^{4,5}$ \\
\hline
\end{tabular}

${ }^{1}$ Data are means \pm SD $(n=3) .{ }^{2}$ Data are means \pm SD $(n=10) .{ }^{3} p($ HEMA $)$ is pristine $p($ HEMA)-based hydrogel. ${ }^{4} \mathrm{p}<0.05$ compared to $\mathrm{p}$ (HEMA). ${ }^{5} \mathrm{p}<0.05$ compared to $\mathrm{p}$ (HEMA)/p(MPC)0.1.

Another key and integral attribute that hydrogels require as a material for colorimetric sensors and ophthalmologic materials such as contact lenses is optical transparency. Here, the optical transmittance of the prepared hydrogels was measured at 300-700 nm and reported as \% transmittance. As shown in Figure 1, all the hydrogels have high transmittance values $(>94 \%)$ that exceed the light transmission required by wearable contact lenses (92\%) [12]. Although a decrease of the transmittance of the hydrogels around 300-320 $\mathrm{nm}$ range was observed which could be due to the presence of the residual photoinitiator, such transmittance decrement is quite typical around the said wavelengths. Li, et al. measured the transmittance of a commercial contact lens, ACUVUE ${ }^{\circledR}$, and found that the transmittance suddenly decreased below $350 \mathrm{~nm}$ due to the UV protection treatment. Typically, benzophenone or benzotriazole is incorporated to absorb the UV light [56]. Nevertheless, the prepared MPC-functionalized hydrogels was considered as being optically transparent, demonstrating the suitability of the prepared hydrogels as contact biomaterials in terms of light transmittance in the range of visible light wavelengths. It is widely recognized that the immiscibility of the monomers largely governs the overall optical transmittance of the hydrogels. Notably, the high \% transmittance of the hydrogels indicate that surface-functionalization of the p(HEMA) hydrogels with $\mathrm{p}(\mathrm{MPC})$ did not result in opaque or phase-separated hydrogels, which is attributed to the excellent miscibility of the MPC with the monomer solutions containing HEMA and EGDMA. 


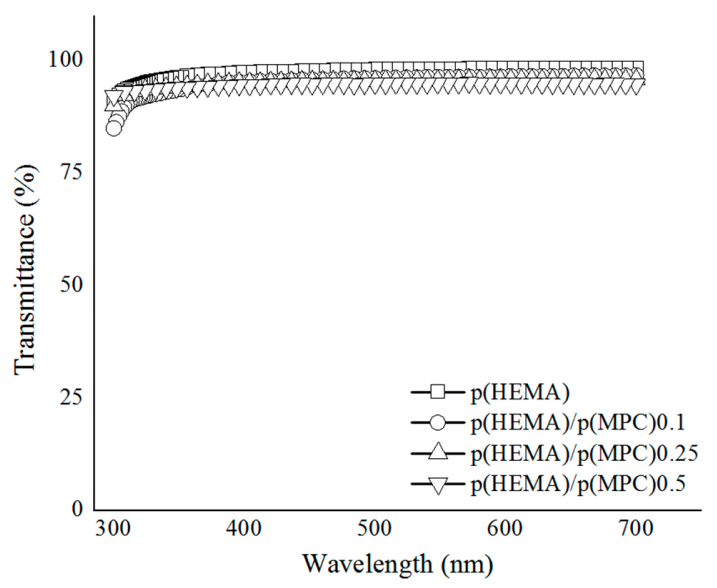

Figure 1. Transmittance spectra of the poly(2-methacryloyloxyethyl phosphorylcholine)-surfacefunctionalized hydrogels.

The surface wettability of the prepared hydrogels was evaluated by carrying out contact angle measurements at the liquid-solid interface. The water contact angle measurements of the hydrogels are shown in Table 1 and Figure 2. The surface-functionalization of p(HEMA) hydrogels with zwitterionic and hydrophilic MPC moieties clearly reduced the contact angles and enhanced the surface wettability. A relatively high-water contact angle of $78.6^{\circ}$ was observed on the surface of the pristine $\mathrm{p}($ HEMA) hydrogels. Subsequently, the surfaces of $\mathrm{p}(\mathrm{HEMA}) / \mathrm{p}(\mathrm{MPC}) 0.1, \mathrm{p}(\mathrm{HEMA}) / \mathrm{p}(\mathrm{MPC}) 0.25$, and $\mathrm{p}(\mathrm{HEMA}) / \mathrm{p}(\mathrm{MPC}) 0.5$, had contact angles of $74.7^{\circ}, 65.0^{\circ}$, and $59.2^{\circ}$, respectively. Furthermore, the statistical analysis of the obtained water contact angles indicated that a significant difference $(p<0.05)$ was observed only after the surface-functionalization of the p(HEMA) substrate with 0.25 M MPC, signifying the crucial role of the zwitterionic MPC played in increasing the wettability of the hydrogel surface. The increased surface wettability of the prepared hydrogels is attributed to the ionic hydration of the phosphorylcholine group in the MPC unit. Such increased surface wettability has also been reported for MPC-surface-functionalized biomaterials [57-59].

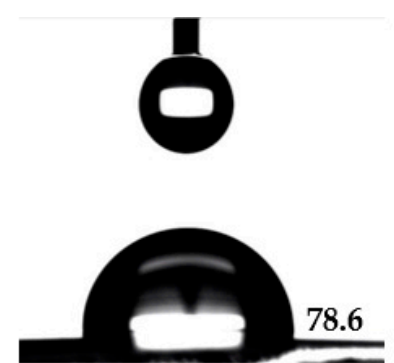

(a)

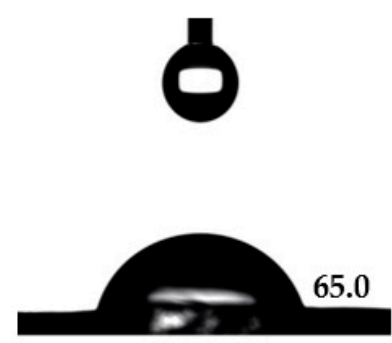

(c)

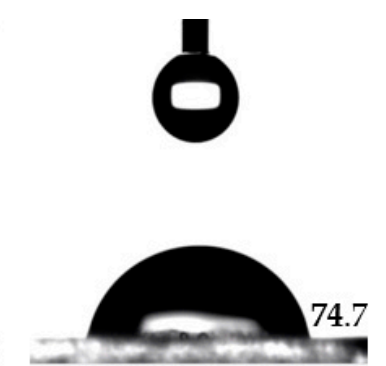

(b)

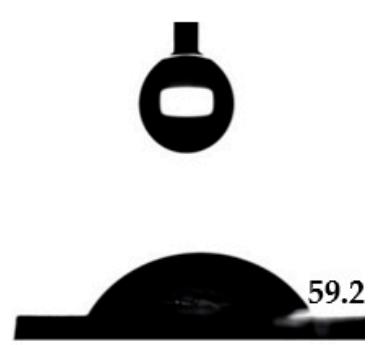

(d)

Figure 2. Contact angles of nanopure water droplets $(4.5 \mu \mathrm{L})$ on (a) pristine p(HEMA) hydrogel; (b) p(HEMA)/p(MPC)0.1 hydrogel; (c) p(HEMA)/p(MPC)0.25 hydrogel; and (d) (HEMA)/p(MPC)0.5 hydrogel. 
In addition, only $\mathrm{p}(\mathrm{HEMA}) / \mathrm{p}(\mathrm{MPC}) 0.5$ among all MPC-modified hydrogels showed significant difference on its water contact angle after being compared to $\mathrm{p}$ (HEMA)/p(MPC)0.1, signifying that the best hydration layer was achieved after employing 0.50 M MPC. It is quite expected that higher MPC concentrations would induce higher wettability than that of the hydrogels modified at lower MPC concentrations, since denser $\mathrm{p}(\mathrm{MPC})$ hydration layers are bound to the surfaces of the hydrogels prepared at high MPC concentrations.

Another important goal in the preparation of biomaterials is to create surfaces with non-fouling properties, to prevent any serious and unwanted biological responses and reactions [60]. Protein deposition onto biological surfaces is affected by several factors including surface chemistry, topology, protein structure, size, and charge [61,62]. Here, we evaluated the adsorption of two model proteins, BSA and lysozyme, to the prepared hydrogels. As shown in Figure 3, the amounts of BSA adsorbed onto the surfaces of $\mathrm{p}(\mathrm{HEMA}) / \mathrm{p}(\mathrm{MPC}) 0.1$, $\mathrm{p}(\mathrm{HEMA}) / \mathrm{p}(\mathrm{MPC}) 0.25$, and $\mathrm{p}(\mathrm{HEMA}) / \mathrm{p}(\mathrm{MPC}) 0.5$ hydrogels were estimated to be 15.7, 12.7, and $12.5 \mu \mathrm{g} /$ hydrogel, respectively. Compared to the $37.8 \mu \mathrm{g} / \mathrm{hydrogel}$ observed for the unmodified hydrogels, this result corresponds to reduced BSA adsorption by approximately $59 \%, 66 \%$, and $67 \%$, respectively.

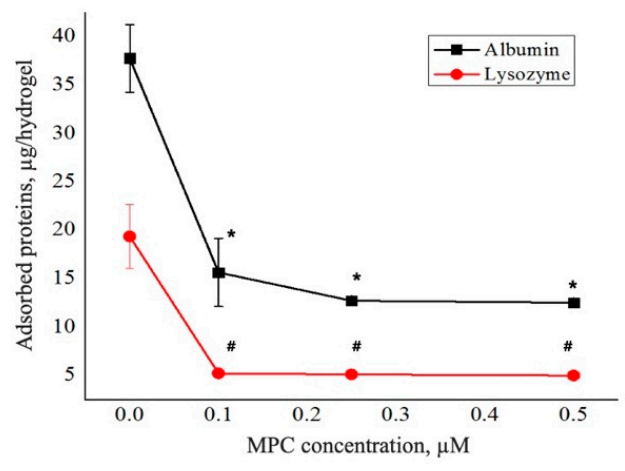

(a)

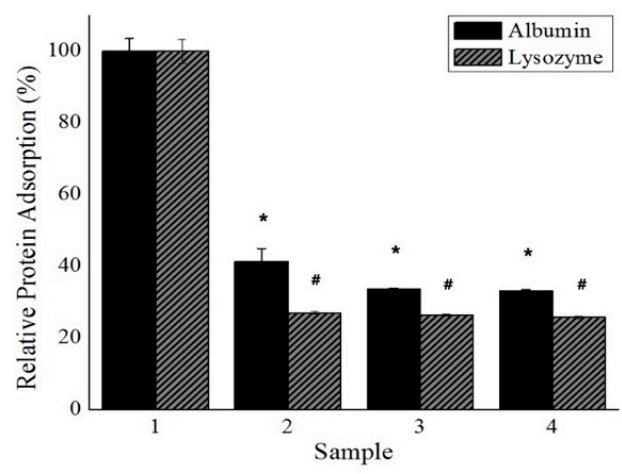

(b)

Figure 3. Protein adsorption profiles of the poly(2-methacryloyloxyethyl phosphorylcholine)-surfacefunctionalized hydrogels in terms of (a) mass of adsorbed proteins per hydrogel and (b) relative protein adsorption $(\%)\left({ }^{*}, \#=p<0.05\right.$ compared to the control). Legend: $1=p($ HEMA $)-H ; 2=$ $\mathrm{p}($ HEMA $) / \mathrm{p}(\mathrm{MPC}) 0.1 ; 3=\mathrm{p}($ HEMA $) / \mathrm{p}($ MPC $) 0.25 ; 4=\mathrm{p}($ HEMA $) / \mathrm{p}(\mathrm{MPC}) 0.5$.

Moreover, MPC-surface-functionalization also decreased lysozyme adsorption on the hydrogels. The unmodified p(HEMA) hydrogels adsorbed approximately $19.4 \mu \mathrm{g} /$ hydrogel of lysozyme onto their surfaces while p(MPC)-modified surfaces adsorbed 5.0-5.2 $\mu \mathrm{g} /$ hydrogel, a roughly 73-74\% reduction in lysozyme adsorption. Moreover, a significant difference $(\mathrm{p}<0.05)$ was observed for both BSA and lysozyme adsorption profiles of all the MPC-functionalized hydrogels when compared to the pristine $\mathrm{p}(\mathrm{HEMA})$ hydrogels. This signifies that the presence of $\mathrm{p}(\mathrm{MPC})$ have contributed to the suppression of BSA and lysozyme adsorption onto the hydrogel surfaces. Furthermore, no significant difference was observed when the mean values of all MPC-functionalized hydrogels were compared to one another. Overall, the obtained protein adsorption profiles of the prepared hydrogels demonstrate that the presence of zwitterionic $\mathrm{p}(\mathrm{MPC})$ layers on the surfaces of the $\mathrm{p}$ (HEMA) hydrogels effectively prevents the adsorption of both BSA and lysozyme. The resistance to protein adsorption is attributed to the interactions between the phosphorylcholine moieties and the surrounding water. A substantial quantity of free water effectively forms a dense hydrated layer around the phosphorylcholine group and acts as a "barrier" that repels proteins and is even thought to inhibit the consequent conformational changes of the adsorbed proteins [63-65]. It has been well established that the reduction of protein adsorption by the $\mathrm{p}(\mathrm{MPC})$ is highly correlated with the water interactions at the polymer surface. Ishihara et al. [66], one of the leading groups investigating the reduction of protein adsorption by MPC-based polymers, observed that the $\mathrm{p}(\mathrm{MPC})$ chains formed unique type of hydration layers when 
compared to other types of hydrophilic polymers such as polyacrylamide [p(AAm)], poly(ethylene oxide) (PEG), and poly(N-vinyl pyrrolidone) [p(VPy)]. The hydration of $\mathrm{p}(\mathrm{MPC})$ mainly arises through hydrophobic hydration of the three methyl groups in the trimethylammonium moiety, inducing an increase in a clathrate cage structure of nearby water molecules and forming an ice-like water state. Hence, MPC-modified surfaces cannot interact strongly with the nearby proteins and cells. Moreover, Ishihara et al. [47] determined the amount of free water on their surfaces using differential scanning calorimetric measurements and observed that these polymers have huge fraction of free water on their surfaces when compared to that of without MPC. In addition, they investigated the change on the conformations of the adsorbed proteins employing ultraviolet and circular dichroism (CD) spectroscopic measurements. The CD spectra revealed that the secondary structure of BSA did not change even after being adsorbed onto the surfaces of MPC-based polymers. The $\alpha$-helix content was also found to be the same level as in the native state, while it dropped by contact with $\mathrm{p}$ (HEMA) substrate. These observations signify that the very high level of free water on the polymer surface provides stabilization to proteins and cells, when these foulants are adsorbed on the polymer surface. Hence, the free water fraction must be one of the more important factors to consider in the protein adsorption resistivity and the subsequent nonbiofouling property of the biomedical polymers. Other groups also reported the excellent performance of the $\mathrm{p}$ (MPC)-functionalized surfaces in the reduction of protein adsorption and highly correlated it with the dense hydration layer formed at the hydrogel surfaces [67-69].

Bacterial adsorption to the prepared hydrogels was investigated using a gram-negative E. coli. The $\mathrm{p}(\mathrm{HEMA}) / \mathrm{p}(\mathrm{MPC}) 0.5$ hydrogel was assessed as the optimum surface-functionalized hydrogel in this series and selected for the bacterial adsorption experiment, after taking into account the results from the protein adsorption experiments. The best hydration layer and better equilibrium swelling were also observed in $\mathrm{p}(\mathrm{HEMA}) / \mathrm{p}$ (MPC) 0.5 hydrogels. The hydrogels were initially immersed in a bacterial suspension of known concentration, incubated for a certain amount of time at $37^{\circ} \mathrm{C}$, removed from the bacterial suspension and re-immersed in a sterile nutrient medium. Then, the bacterial concentration was evaluated at pre-determined time intervals from 1 to $24 \mathrm{~h}$ [70] by measuring the optical density of the bacterial suspensions using a UV-spectrophotometer. As shown in Figure 4, there is a significant distinction between the adherent bacterial colonies of the two samples. The suspensions containing the $\mathrm{p}(\mathrm{MPC})$-surface-functionalized hydrogels have lower absorbance values than those of the unmodified hydrogels throughout the 24-h incubation time. These lower absorbance values of the bacterial suspensions correspond to bacterial adsorption values that are reduced by approximately $10-73 \%$ of the values of pristine $\mathrm{p}$ (HEMA) hydrogels throughout the 24 -h incubation period.

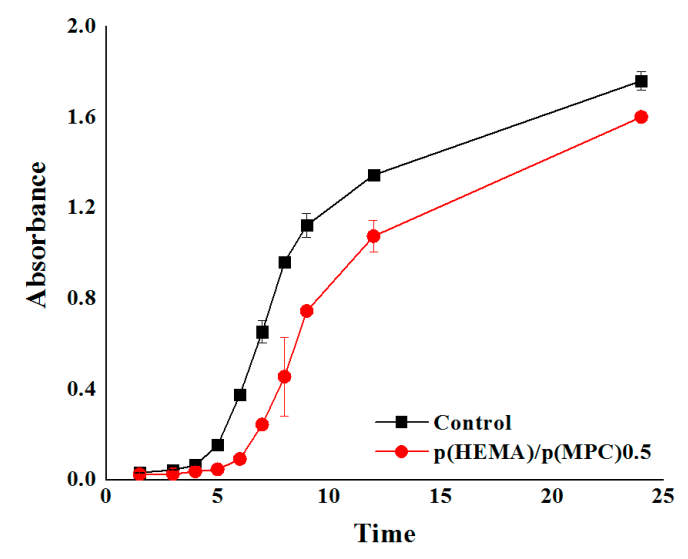

Figure 4. Bacterial adsorption profiles of the poly(2-methacryloyloxyethyl phosphorylcholine)-surfacefunctionalized hydrogels.

Similar to the explanation of protein desorption from prepared hydrogels, the observed reduction in bacterial adsorption onto the hydrogel surfaces may be attributed to the dense hydration layer formed by the zwitterionic $p(\mathrm{MPC})$ on the hydrogel surface $[35,36]$. This hydration layer leads to 
a strong repulsive force against surrounding microorganisms, which prevents them from gaining anchorage and subsequently results in reduced levels of bacterial adsorption onto the hydrogel surfaces.

\section{Conclusions}

Herein, we demonstrate that the surface-functionalization of the p(HEMA) substrate with hydrophilic and zwitterionic MPC moieties is a viable approach for developing functional biomaterials with improved resistance to protein and bacterial adsorption. The hydrogels were prepared via three-step synthetic pathway consisting of synthesis of the $\mathrm{p}$ (HEMA) substrate, adsorption of a photosensitizer onto the hydrogel surfaces, and UV-induced free radical polymerization of the MPC monomers. The decrement in water contact angles of the MPC-modified hydrogels confirms the intrinsic ionic functionality of the incorporated p(MPC), which enhances the surface wettability of the prepared hydrogels. Remarkably, the presence of zwitterionic MPC moieties significantly decreases protein and bacterial adsorption to the modified hydrogels, due to the dense hydration layers formed by the polymerized MPC on the surfaces of the hydrogels. The results described herein demonstrate the feasibility of developing hydrogels that possess superior antifouling and antimicrobial properties. These novel multifunctional biomaterials demonstrate promising potential for various biomedical and biotechnological applications.

Author Contributions: Conceptualization, J.S.K.; methodology, H.-J.K. and J.-P.J.; software, H.-J.K., J.-P.J. and S.C.; validation, H.-J.K., J.-P.J., G.M.L. and S.C.; formal analysis, T.P.V., G.M.L. and W.Y.L.; investigation, T.P.V. and W.Y.L.; resources, H.-J.K. and J.-P.J.; data curation, H.-J.K. and J.-P.J.; writing-original draft preparation, T.P.V., J.S.K. and J.-P.J.; writing-review and editing, T.P.V., W.Y.L., H.-J.K., J.S.K. and J.-P.J.; visualization, T.P.V., G.M.L. and W.Y.L.; supervision, H.-J.K. and J.-P.J.; project administration, J.S.K. and J.-P.J.; funding acquisition, H.-J.K. and J.-P.J. All authors have read and agreed to the published version of the manuscript.

Funding: This research received no external funding.

Acknowledgments: This study was supported by research funds provided by Chosun University in 2018.

Conflicts of Interest: The authors declare no conflict of interest.

\section{References}

1. Marklein, R.A.; Burdick, J.A. Spatially controlled hydrogel mechanics to modulate stem cell interactions. Soft Matter. 2010, 6, 136-143. [CrossRef]

2. Kim, B.; Kang, B.; Vales, T.P.; Yang, S.K.; Lee, J.; Kim, H.J. Polyphenol-Functionalized Hydrogels Using an Interpenetrating Chitosan Network and Investigation of Their Antioxidant Activity. Macromol. Res. 2018, 26, 35-39. [CrossRef]

3. Parhi, R. Cross-Linked Hydrogel for Pharmaceutical Applications: A Review. Adv. Pharm. Bull. 2017, 7, 515-530. [CrossRef] [PubMed]

4. Jones, D.S.; McLaughlin, D.W.J.; McCoy, C.P.; Gorman, S.P. Physicochemical characterisation and biological evaluation of hydrogel-poly ( $\varepsilon$-caprolactone) interpenetrating polymer networks as novel urinary biomaterials. Biomaterials 2005, 26, 1761-1770. [CrossRef] [PubMed]

5. Flynn, L.; Dalton, P.D.; Shoichet, M.S. Fiber templating of poly (2-hydroxyethyl methacrylate) for neural tissue engineering. Biomaterials 2003, 24, 4265-4272. [CrossRef]

6. Michelsen, V.B.; Moe, G.; Strøm, M.B.; Jensen, E.; Lygre, H. Quantitative analysis of TEGDMA and HEMA eluted into saliva from two dental composites by use of GC/MS and tailor-made internal standards. Dent. Mater. 2008, 24, 724-731. [CrossRef]

7. Dziubla, T.D.; Torjman, M.C.; Joseph, J.I.; Murphy-Tatum, M.; Lowman, A.M. Evaluation of porous networks of poly (2-hydroxyethyl methacrylate) as interfacial drug delivery devices. Biomaterials 2001, 22, 2893-2899. [CrossRef]

8. Kwon, O.H.; Nho, Y.C.; Lee, Y.M. Radiation-induced copolymerization of 2-hydroxyethyl methacrylate and polyethylene glycol methacrylate, and its protein adsorption and bacterial attachment. J. Ind. Eng. Chem. 2003, 9, 138-145.

9. Lloyd, A.W.; Faragher, R.G.A.; Denyer, S.P. Ocular biomaterials and implants. Biomaterials 2001, 22, 769-785. [CrossRef] 
10. Parsons, C.; Jones, D.S.; Gorman, S.P. The intraocular lens: Challenges in the prevention and therapy of infectious endophthalmitis and posterior capsular opacification. Expert Rev. Med. Devices 2005, 2, 161-173. [CrossRef]

11. Abraham, S.; Brahim, S.; Ishihara, K.; Guiseppi-Elie, A. Molecularly engineered p (HEMA)-based hydrogels for implant biochip biocompatibility. Biomaterials 2005, 26, 4767-4778. [CrossRef] [PubMed]

12. Bai, T.; Zhang, P.; Han, Y.; Liu, Y.; Liu, W.; Zhao, X.; Lu, W. Construction of an ultrahigh strength hydrogel with excellent fatigue resistance based on strong dipole-dipole interaction. Soft Matter. 2011, 7, 2825-2831. [CrossRef]

13. Tomić, S.L.; Suljovrujić, E.H.; Filipović, J.M. Biocompatible and bioadhesive hydrogels based on 2-hydroxyethyl methacrylate, monofunctional poly (alkylene glycol) s and itaconic acid. Polym. Bull. 2006, 57, 691-702. [CrossRef]

14. Carr, L.R.; Xue, H.; Jiang, S. Functionalizable and nonfouling zwitterionic carboxybetaine hydrogels with a carboxybetaine dimethacrylate crosslinker. Biomaterials 2011, 32, 961-968. [CrossRef] [PubMed]

15. Bozukova, D.; Pagnoulle, C.; De Pauw-Gillet, M.C.; Ruth, N.; Jérôme, R.; Jérôme, C. Imparting antifouling properties of poly(2-hydroxyethyl methacrylate) hydrogels by grafting poly(oligoethylene glycol methyl ether acrylate). Langmuir 2008, 24, 6649-6658. [CrossRef] [PubMed]

16. Goda, T.; Ishihara, K.; Miyahara, Y. Critical update on 2-methacryloyloxyethyl phosphorylcholine (MPC) polymer science. J. Appl. Polym. Sci. 2015, 132, 1-10. [CrossRef]

17. Lim, H.; Kim, H.; Jun, J. Development of Hyaluronic Acid-Functionalized Hydrogel Lens and Characterization of Physical Properties and Lysozyme Adsorption. J. Korean Ophthalmic Opt. Soc. 2015, 20, 285-291. [CrossRef]

18. Perrino, C.; Lee, S.; Choi, S.W.; Maruyama, A.; Spencer, N.D. A biomimetic alternative to poly (ethylene glycol) as an antifouling coating: Resistance to nonspecific protein adsorption of poly (L-lysine)-graft-dextran. Langmuir 2008, 24, 8850-8856. [CrossRef]

19. Heo, S.; Jeon, Y.S.; Kim, S.I.; Kim, S.H.; Kim, J.H. Bioinspired adhesive coating on PET film for antifouling surface modification. Macromol. Res. 2014, 22, 203-209. [CrossRef]

20. Thissen, H.; Gengenbach, T.; du Toit, R.; Sweeney, D.F.; Kingshott, P.; Griesser, H.J.; Meagher, L. Clinical observations of biofouling on PEO coated silicone hydrogel contact lenses. Biomaterials 2010, 31, 551-5519. [CrossRef]

21. Rahman, M.M.; Chun, H.H.; Park, H. Preparation and properties of waterborne polyurethane-silane: A promising antifouling coating. Macromol. Res. 2011, 19, 8-13. [CrossRef]

22. Kim, H.J.; Ryu, G.C.; Jeong, K.S.; Jun, J. Hydrogel lenses functionalized with polysaccharide for reduction of protein adsorption. Macromol. Res. 2014, 23, 74-78. [CrossRef]

23. Ishihara, K.; Ueda, T.; Nakabayashi, N. Preparation of phospholipid polylners and their properties as polymer hydrogel membranes. Polym. J. 1990, 22, 355. [CrossRef]

24. Ng, V.W.L.; Chan, J.M.W.; Sardon, H.; Ono, R.J.; Garcia, J.M.; Yang, Y.Y.; Hedrick, J.L. Antimicrobial hydrogels: A new weapon in the arsenal against multidrug-resistant infections. Adv. Drug Deliv. Rev. 2014, 78, 46-62. [CrossRef] [PubMed]

25. Zhang, L.; Cao, Z.; Bai, T.; Carr, L.; Ella-Menye, J.R.; Irvin, C.; Ratner, B.D.; Jiang, S. Zwitterionic hydrogels implanted in mice resist the foreign-body reaction. Nat. Biotechnol. 2013, 31, 553. [CrossRef] [PubMed]

26. Olivier, A.; Meyer, F.; Raquez, J.M.; Damman, P.; Dubois, P. Surface-initiated controlled polymerization as a convenient method for designing functional polymer brushes: From self-assembled monolayers to patterned surfaces. Prog. Polym. Sci. 2012, 37, 157-181. [CrossRef]

27. Koepsel, J.T.; Murphy, W.L. Patterned Self-Assembled Monolayers: Efficient, Chemically Defined Tools for Cell Biology. Chem. Bio. Chem. 2012, 13, 1717-1724. [CrossRef]

28. Galvin, C.J.; Genzer, J. Applications of surface-grafted macromolecules derived from post-polymerization modification reactions. Prog. Polym. Sci. 2012, 37, 871-906. [CrossRef]

29. Yang, W.J.; Pranantyo, D.; Neoh, K.G.; Kang, E.T.; Teo, S.L.M.; Rittschof, D. Layer-by-layer click deposition of functional polymer coatings for combating marine biofouling. Biomacromolecules 2012, 13, 2769-2780. [CrossRef]

30. Zhu, X.; Guo, S.; Jańczewski, D.; Parra Velandia, F.J.; Teo, S.L.M.; Vancso, G.J. Multilayers of fluorinated amphiphilic polyions for marine fouling prevention. Langmuir 2013, 30, 288-296. [CrossRef]

31. Kim, M.; Kim, Y.J.; Gwon, K.; Tae, G. Modulation of cell adhesion of heparin-based hydrogel by efficient physisorption of adhesive proteins. Macromol. Res. 2012, 20, 271-276. [CrossRef] 
32. Ahn, J.; Sohn, E.H.; Bang, S.H.; Kang, J.; Kim, T.; Hong, H.; Kim, S.E.; Kim, B.S.; Yoon, J.; Lee, J.C. Biocompatible Ag nanoparticle-embedded poly (2-hydroxyethyl methacrylate) derivative films with bacterial adhesion-resistant and antibacterial properties. Macromol. Res. 2014, 22, 337-343. [CrossRef]

33. Iwasaki, Y.; Nakabayashi, N.; Ishihara, K. Preservation of platelet function on 2-methacryloyloxyethyl phosphorylcholine-graft polymer as compared to various water-soluble graft polymers. J. Biomed. Mater. Res. 2001, 57, 72-78. [CrossRef]

34. Xu, Y.; Takai, M.; Ishihara, K. Protein adsorption and cell adhesion on cationic, neutral, and anionic 2-methacryloyloxyethyl phosphorylcholine copolymer surfaces. Biomaterials 2009, 30, 4930-4938. [CrossRef] [PubMed]

35. Choi, J.R.; Yong, K.W.; Choi, J.Y.; Cowie, A.C. Recent advances in photo-crosslinkable hydrogels for biomedical applications. BioTechniques 2019, 66, 40-53. [CrossRef] [PubMed]

36. Jiang, S.; Cao, Z. Ultralow-fouling, functionalizable, and hydrolyzable zwitterionic materials and their derivatives for biological applications. Adv. Mater. 2010, 22, 920-932. [CrossRef] [PubMed]

37. Chen, S.; Zheng, J.; Li, L.; Jiang, S. Strong resistance of phosphorylcholine self-assembled monolayers to protein adsorption: Insights into nonfouling properties of zwitterionic materials. J. Am. Chem. Soc. 2005, 127, 14473-14478. [CrossRef]

38. He, M.; Gao, K.; Zhou, L.; Jiao, Z.; Wu, M.; Cao, J.; You, X.; Cai, Z.; Su, Y.; Jiang, Z. Zwitterionic materials for antifouling membrane surface construction. Acta Biomater. 2016, 40, 142-152. [CrossRef]

39. Schroeder, M.E.; Zurick, K.M.; McGrath, D.E.; Bernards, M.T. Multifunctional polyampholyte hydrogels with fouling resistance and protein conjugation capacity. Biomacromolecules 2013, 14, 3112-3122. [CrossRef]

40. Chen, S.; Li, L.; Zhao, C.; Zheng, J. Surface hydration: Principles and applications toward low-fouling/nonfouling biomaterials. Polymer 2010, 51, 5283-5293. [CrossRef]

41. Bretscher, M.S.; Raff, M.C. Mammalian plasma membranes. Nature 1975, 258, 43. [CrossRef]

42. Park, J.U.; Ham, J.; Kim, S.; Seo, J.H.; Kim, S.H.; Lee, S.; Min, H.J.; Choi, S.; Choi, R.M.; Kim, H.; et al. Alleviation of capsular formations on silicone implants in rats using biomembrane-mimicking coatings. Acta Biomater. 2014, 10, 4217-4225. [CrossRef] [PubMed]

43. Iwasaki, Y.; Sawada, S.I.; Nakabayashi, N.; Khang, G.; Lee, H.B.; Ishihara, K. The effect of the chemical structure of the phospholipid polymer on fibronectin adsorption and fibroblast adhesion on the gradient phospholipid surface. Biomaterials 1999, 20, 2185-2191. [CrossRef]

44. Ishihara, K.; Tanaka, S.; Furukawa, N.; Nakabayashi, N.; Kurita, K. Improved blood compatibility of segmented polyurethanes by polymeric additives having phospholipid polar groups. I. Molecular design of polymeric additives and their functions. J. Biomed. Mater. Res. A 1996, 32, 391-399. [CrossRef]

45. Yoneyama, T.; Ito, M.; Sugihara, K.I.; Ishihara, K.; Nakabayashi, N. Small diameter vascular prosthesis with a nonthrombogenic phospholipid polymer surface: Preliminary study of a new concept for functioning in the absence of pseudo-or neointima formation. Artif. Organs 2000, 24, 23-28. [CrossRef]

46. Zhang, Z.; Chen, S.; Chang, Y.; Jiang, S. Surface grafted sulfobetaine polymers via atom transfer radical polymerization as superlow fouling coatings. J. Phys Chem. B 2006, 110, 10799-10804. [CrossRef] [PubMed]

47. Ishihara, K.; Nomura, H.; Mihara, T.; Kurita, K.; Iwasaki, Y.; Nakabayashi, N. Why do phospholipid polymers reduce protein adsorption? J. Biomed. Mater. Res. 1998, 39, 323-330. [CrossRef]

48. Kim, J.; Somorjai, G.A. Molecular packing of lysozyme, fibrinogen, and bovine serum albumin on hydrophilic and hydrophobic surfaces studied by infrared-visible sum frequency generation and fluorescence microscopy. J. Am. Chem. Soc. 2003, 125, 3150-3158. [CrossRef]

49. Polakova, L.; Raus, V.; Kostka, L.; Braunova, A.; Pilar, J.; Lobaz, V.; Pánek, J.; Sedláková, Z. Antioxidant properties of 2-hydroxyethyl methacrylate-based copolymers with incorporated sterically hindered amine. Biomacromolecules 2015, 16, 2726-2734. [CrossRef]

50. Kiritoshi, Y.; Ishihara, K. Preparation of cross-linked biocompatible poly (2-methacryloyloxyethyl phosphorylcholine) gel and its strange swelling behavior in water/ethanol mixture. J. Biomater. Sci. Polym. Ed. 2002, 13, 213-224. [CrossRef]

51. Jee, J.P.; Kim, H.J. Development of hydrogel lenses with surface-immobilized PEG layers to reduce protein adsorption. Bull. Korean Chem. Soc. 2015, 36, 2682-2687. [CrossRef]

52. Moore, W.M.; Hammond, G.S.; Foss, R.P. Mechanisms of photoreactions in solutions. I. Reduction of benzophenone by benzhydrol. J. Am. Chem. Soc. 1961, 83, 2789-2794. [CrossRef] 
53. Yin, Y.; Yang, Y.; Xu, H. Swelling behavior of hydrogels for colon-site drug delivery. J. Appl. Polym. Sci. 2002, 83, 2835-2842. [CrossRef]

54. Ahmed, T.A.E.; Hincke, M.T. Strategies for articular cartilage lesion repair and functional restoration. Tissue Eng. Part B Rev. 2010, 16, 305-329. [CrossRef] [PubMed]

55. Garrett, Q.; Laycock, B.; Garrett, R.W. Hydrogel lens monomer constituents modulate protein sorption. Investig. Ophthalmol. Vis. Sci. 2000, 41, 1687-1695.

56. Li, L.; Wang, J.H.; Xin, Z. Synthesis and biocompatibility of a novel silicone hydrogel containing phosphorylcholine. Eur. Polym. J. 2011, 47, 1795-1803. [CrossRef]

57. Iwata, R.; Satoh, R.; Iwasaki, Y.; Akiyoshi, K. Covalent immobilization of antibody fragments on well-defined polymer brushes via site-directed method. Colloids Surf. B Biointerfaces 2008, 62, 288-298. [CrossRef]

58. Kobayashi, M.; Terayama, Y.; Hosaka, N.; Kaido, M.; Suzuki, A.; Yamada, N.; Torikai, N.; Ishihara, K.; Takahara, A. Friction behavior of high-density poly (2-methacryloyloxyethyl phosphorylcholine) brush in aqueous media. Soft Matter 2007, 3, 740-746. [CrossRef]

59. Ketelson, H.A.; Perry, S.S.; Sawyer, W.G.; Jacob, J.T. Exploring the Science and Technology of Contact Lens Comfort. Comfort. Contact Lens Spectr. 2011, 26, 30-36.

60. Seo, J.H.; Matsuno, R.; Konno, T.; Takai, M.; Ishihara, K. Surface tethering of phosphorylcholine groups onto poly (dimethylsiloxane) through swelling-deswelling methods with phospholipids moiety containing ABA-type block copolymers. Biomaterials 2008, 29, 1367-1376. [CrossRef]

61. Ratner, B.D.; Bryant, S.J. Biomaterials: Where we have been and where we are going. Annu. Rev. Biomed. Eng. 2004, 6, 41-75. [CrossRef]

62. Kung, F.C.; Yang, M.C. Effect of conjugated linoleic acid immobilization on the hemocompatibility of cellulose acetate membrane. Colloids Surf. B Biointerfaces 2006, 47, 36-42. [CrossRef] [PubMed]

63. Sheng, Q.; Schulten, K.; Pidgeon, C. Molecular dynamic simulation of immobilized artificial membranes. J. Phys. Chem. 1995, 99, 11018-11027. [CrossRef]

64. Chapman, D. Biomembranes and new hemocompatible materials. Langmuir 1993, 9, 39-45. [CrossRef]

65. Goda, T.; Matsuno, R.; Konno, T.; Takai, M.; Ishihara, K. Protein adsorption resistance and oxygen permeability of chemically crosslinked phospholipid polymer hydrogel for ophthalmologic biomaterials. J. Biomed. Mater. Res. Part B Appl. Biomater. 2009, 89, 184-190. [CrossRef]

66. Ishihara, K.; Mu, M.; Konno, T.; Inoue, Y.; Fukazawa, K. The unique hydration state of poly (2-methacryloyloxyethyl phosphorylcholine). J. Biomater. Sci. Polym. Ed. 2017, 28, 884-899. [CrossRef] [PubMed]

67. Wang, J.J.; Liu, F. Photoinduced graft polymerization of 2-methacryloyloxyethyl phosphorylcholine on silicone hydrogels for reducing protein adsorption. J. Mater. Sci. Mater. Med. 2011, 22, 2651-2657. [CrossRef]

68. Chae, K.H.; Jang, Y.M.; Kim, Y.H.; Sohn, O.J.; Rhee, J.I. Anti-fouling epoxy coatings for optical biosensor application based on phosphorylcholine. Sens. Actuators B Chem. 2007, 124, 153-160. [CrossRef]

69. Huang, X.D.; Yao, K.; Zhang, H.; Huang, X.J.; Xu, Z.K. Surface modification of silicone intraocular lens by 2-methacryloyloxyethyl phosphoryl-choline binding to reduce Staphylococcus epidermidis adherence. Clin. Exp. Ophthalmol. 2007, 35, 462-467. [CrossRef]

70. Rojas, J.J.; Ochoa, V.J.; Ocampo, S.A.; Muñoz, J.F. Screening for antimicrobial activity of ten medicinal plants used in Colombian folkloric medicine: A possible alternative in the treatment of non-nosocomial infections. BMC Complement. Altern. Med. 2006, 6, 2. [CrossRef]

(C) 2020 by the authors. Licensee MDPI, Basel, Switzerland. This article is an open access article distributed under the terms and conditions of the Creative Commons Attribution (CC BY) license (http://creativecommons.org/licenses/by/4.0/). 